\title{
Lütfi Sunar, Alexis De Tocqueville: Modern Çağın Çelişkileri Karşısında Bir Düşünür, İstanbul: Ketebe, 2019, 207 s.
}

Değerlendiren: Nazife Hande Aksu

19. yüzyıl Fransız siyasetinin önemli simalarından Tocqueville, inşa ettiği düşünceleri ve eserleri ile Avrupalı araştırmacıların sıkça ilgi alanına girmektedir. Buna karşllık onun düşünceleri ve kimliği Türkiye'deki çalışmalara nadiren konu olmaktadır. Modern toplum, demokrasi, öteki sorunu, despotizm, merkeziyetçilik, sivil toplum gibi konularda okuma yapmak isteyenler için Tocqueville, oldukça önemli bir isimdir. Bu bağlamda Sunar, modern toplumun nasıl oluştuğuna ve bu toplumun sorunlarının neler olduğuna dair bir fikir edinmek isteyenlerin Tocqueville'e başvurmasının zorunlu olduğunu belirtir (s. 9). Tocqueville, kendi döneminin kaotik durumu ile modern toplumun çelişkileri karşısında kendi düşüncesini kurmuştur. Baktığımız zaman onun düşüncelerini bir kaos döneminin paradoksal ifadeleri olarak görebiliriz. Bu sebeple onun çelişkileri ve dönemin diğer düşünürlerinden ayrılan fikrî yapısı, onu kategorize etmemizi ve doğru bir şekilde anlamamızı zorlaştıran hususlardandır. Ayrıca onunla ilgili tam bir külliyatın hazırlanamamış olması da onun düşüncelerini takip etmemizi zorlaştırmaktadır (s. 9). Bunun yanı sıra Sunar, Tocqueville'in ulaştığı ünün onu tam olarak anlamamızın önündeki bir engel olduğunu da sıkça belirtir (s. 9). Zira Tocqueville denildiğinde akla ilk gelen Amerika'da Demokrasi isimli çalışması olmaktadır. Yayınlandığı dönemde büyük bir şöhret kazanan eser kısa sürede önemli bir yapıt olarak demokrasi teorisini öğrenmek isteyenlerin raflarında yerini almıştır. Ancak bu çalışmanın da ne kadar eksiksiz bir şekilde okunduğu ayrı bir tartışma konusudur. Bu tür sebeplerden dolayı birçok düşünür onu ele alırken onun düşüncelerini farklı sınıflara dâhil etmişlerdir. Kısacası onun düşüncesini takip edip doğru bir şekilde anlamak oldukça zordur. Bu nedenle Lütfi Sunar'ın kaleme aldığı Alexis De Tocqueville: Modern Çağın Çelişkileri

@ Yüksel Lisans Öğrencisi. Ankara Sosyal Bilimler Üniversitesi. as.aksa.18a@gmail.com

(iD) https://orcid.org/0000-0002-3831-4991 
Karşısında Bir Düşünür isimli çalışma, Tocqueville'in düşüncelerini sistematik bir biçimde tanımak için oldukça önemlidir.

Sunar, çalışmayı kaleme alma sürecinin Tocqueville'e benzer olduğunu dile getirir. Nasıl ki onun aklında, Amerika'yı seyahate çıkacağı vakit Amerika'da Demokrasi'yi kaleme almak yoktu, Sunar'da benzer şekilde Amerika'da bulunurken Tocqueville'i inceleyip onun hakkında eser ortaya koymak gibi bir düşünceye sahip değildi. Ancak modern Batı düşüncesinde öteki ile ilgili bir çalışma planladığını belirten yazar, konunun kendiliğinden Tocqueville’e evrildiğinden bahsetmektedir.

Tocqueville, Batı'nın modern dönem çelişkilerini ve dönemin sancılı sürecini takip etmek isteyenler için oldukça önemli bir kaynaktır. Aynı şekilde elimizdeki bu kitap, Tocqueville'in şahsiyetini, düşünce ve sosyal teorisini öğrenmek isteyen okuyuculara anlamlı bir bütün sunmaktadır. Bu sebeple Sunar, hedefinin, Tocqueville'in düşüncelerini bağlamsallaştırarak alana önemli ölçüde destek olmak olduğunu dile getirir.

Türkiye'de müstakil olarak Tocqueville üzerinde yapılan çalışmalara kısa bir göz attığımızda genellikle bu çalışmaların siyaset bilimciler tarafından ortaya konulduğu söyleyebiliriz. Hukuk, ekonomi, tarih ve sosyoloji bağlamında Tocqueville’i konu edinen çalışmalar da vardır. Ancak bunların sınırlı sayıda olduğunu dile getirebiliriz. Bu bağlamda toplum bilimi çerçevesinde konunun ele alındığı çalışmalar oldukça azdır. Bu çalışmalar genellikle Tocqueville'in demokrasi teorisi, sivil toplum görüşleri ve liberalizm çerçevesinde ele alınmıştır. Yani bu çalışmalar bütünlüklü olarak Tocqueville'in siyasi ve sosyal teorisini ele almayıp onun belirli bir yönü ile kendilerini sınırlamışlardır. Ayrıca yapılan bu araştırmalarda Tocqueville’in çalışmalarının yalnızca bir kısmı kaynak olarak kullanılmıştır. Bunun yanı sıra Türkiye'de sosyal sermaye, sivil toplum ve liberalizm ile ilgili ortaya konan araştırmalarda Tocqueville'in izlerine rastlamak mümkündür. Bu arka plandan hareketle Çağla'nın (2007) Tocqueville'in demokrasi teorisini özgürlük bağlamında konu edindiği kitabını, Özyurt'un (2007) modern toplumun karakterini Tocqueville üzerinden kaleme aldığı yazısını, Gürbüz'ün (2012) Tocqueville’in Cezayir raporlarında kâğıda döktüğü doğa yasalarını eleştirel bir üslupla işlediği makalesini, Türkiye'de yapılan çalışmalara örnek olarak verebiliriz. Değindiğimiz bu çalışmalar, ele aldıkları meseleleri, Tocqueville etrafında tartışmaları bakımından kayda değerdir. Ancak Tocqueville ile ilgili yazılar hem nicelik olarak yetersiz hem de ele aldıkları konular açısından dar kapsamlıdır. Bu tür sebeplerden olsa gerek yazar, çalışmada literatüre ilişkin bir bilgi sunmaktan ziyade bu konuyla ilgili ülkemizde fazla bir uğraşın olmamasından yakınır. Sunar'ın Tocqueville'in çalışmalarına karşı detaylı 
bir şekilde yaptığı inceleme ve onu bütünlüklü bir şekilde ele alıp sosyal teorisini ortaya koyması, Türkiye'de yapılan çalışmalara büyük bir katkı sunmaktadır. Ayrıca ülkemizde Tocqueville’in tanınması açısından kitap, oldukça önemlidir.

Çalışma giriş ve sonuç bölümlerinin yanında sekiz ana bölümden oluşmaktadır. Her bölüm kendi içinde alt başlıklara ayrılarak ele alınmıştır. Bölüm başlıkları içerikten daha kapsamlı bir şekilde verilmiştir. Ancak geniş tutulan başlıklar, çalışmanın etkisini azaltmamaktadır. Sunar tarafından bazı başlıklar gerçekten çarpıcı bir biçimde seçilmiştir. Örneğin; Cezayir seyahati ile ilgili olan bölüme "Cezayir'e Seyahat: Binbir Gece Masalının Kıyısında” başlığının verilmesi ya da sömürgecilikle ilgili bölüme "Sömürgecilik: Ulusu Tazeleyen Zulüm” denilmesi, okuyucuya ilgi çekici gelebilmektedir. Sonuç bölümünün ardından Tocqueville'in hayatını daha rahat bir şekilde takip edebileceğimiz bir kronoloji sunulmuştur. Bunun ardından Tocqueville'in eserlerinin çevirileri hakkında bilgi verilmiş ve ileri okumalar için kitap önerileri sunulmuştur. Yazar, çalışma boyunca sıklıkla kullandığı terimleri, çalışmanın sonunda sözlük olarak okuyucuya sunar. Onun bu tutumu, okuyucuların kendi zihnindeki tanımlardan ziyade çalışmanın mahiyetine uygun düşen tanımlamaları bilmeleri açısından oldukça önemlidir. Böylece okuyucu, temel kavramların farkında olarak daha sağlam bir okuma yapabilmektedir. Ancak sözlük bölümü dikkatli olmayan okuyucuların gözünden kaçabilmektedir. Bu sebeple çalışmanın üzerine kurulduğu temel kavramlara kısaca giriş bölümünde değinilmesinin daha anlaşılır bir okuma sunabileceği kanaatindeyiz. Son olarak kaynakça ile kitap nihayete erdirilir. Kaynakçayı incelediğimizde ve kısaca Sunar'ın çalışmalarına göz gezdirdiğimizde onun araştırmalarının sağlam bir arka plana dayandığını kolayca görebiliriz.

Giriş bölümünde yazar, kitabın ana çerçevesini vermiştir. Ancak bundan önce Tocqueville'in ekseriyetle üzerinde durduğu iki temel sorunu okuyucuya sunmuştur. Bunlardan birincisi, Fransa'da kurulan yeni düzen, ikincisi ise sömürgecilik-kölelik meselesidir. Bunların yanı sıra çalışmalarda önemli bir yanılsamaya sebep olan Tocqueville'in ulaştığı ünden de ayrı bir alt başlık altında bahsetmeyi ihmal etmemiştir. Ana ekseni ile çalışma, bir masa başı düşünürü olmayan, seyahatler üzerine kurulu bir düşünce yapısı inşa eden Tocqueville'in sömürgecilik, kölelik, despotizm, eşitlik ve demokrasiye dair sosyal ve siyasi düşüncelerini ihtiva etmektedir. Baktığımız zaman onun düşünceleri kendi zamanını aşmış hatta gelecekle ilgili kehanetleri tutmuştur. Ancak bir kişinin düşünceleri kendi zamanını aşsa dahi onun fikir dünyasını anlamak için yaşadığı zamana ve hayata bakmak oldukça önemlidir. $\mathrm{Bu}$ sebeple yazar öncelikle Tocqueville'in hayatını ele alarak onu düşüncelerinin oturduğu zemini okuyuculara sunmuştur. 
Sunar, birinci bölümde Tocqueville’in inişli çıkışlı hayatını konu edinmiştir. O, yaşadığ 1 dönemin kendi havasına göre çalkantılı bir dönemde öne çıkarken diğer bir dönemde geri plana düşüyordu. Bu sebeple özelde Fransa'nın genelde ise modern Batı dünyasının fırtınalı havasının onun düşüncelerine sindiğini söyleyebiliriz. Bu bağlamda Tocqueville'i tartışılır kılan önemli bir özelliği, düşüncelerindeki çelişkiler ve muğlaklıklardır. Onun düşüncelerinin oluşumuna etki eden faktörleri; Fransız Devrimi, aristokrasiden burjuvaziye geçiş, hükûmetin sık sık el değiştirmesi, Cezayir'in Fransız sömürgecilerin eline geçmesi ve buna bağlı olarak meydana gelen sömürgecilik-kölelik tartışmalarının yaşanması olarak betimleyebiliriz. Kısacası kaotik geçiş döneminin doğurduğu sonuçlar olarak ifade edersek herhalde yanılmış olmayız. Bu olayların yanı sıra birçok düşünür, Tocqueville'in düşüncelerinin oluşumuna destek vermişlerdir. Bunları Rousseau, Pascal, Montesquieu gibi düşünürler olarak sıralayabiliriz (s. 40). Ancak bunları söylerken Tocqueville'in dönemin diğer siyaset ve sosyal bilimcilerine benzemediği ve kendine özgü biri olduğu hususu da çalışmada ayrıca vurgulanır. İlk bölümde Tocqueville'in tanıtılması, kitabın ileri bölümlerinin anlaşılması için oldukça önemlidir. Bu bölümün akabinde Sunar, farklı bölüm başlıkları altında; Tocqueville'in yaptığı seyahatlere, onun düşünce ve görüşlerine, eserlerine, çelişkilerine yer vermiştir. Sunar, hangi bölüm başlığı altında neleri işleyeceğini ayrıntılı bir şekilde giriş bölümünde dile getirir.

Bir düşünceyi anlamanın en önemli yollarından biri, o düşünceyi ortaya koyan kişiyi anlamaktır. Bu bağlamda Sunar öncelikli olarak Tocqueville'in hayatını okuyucuya sunduktan sonra "Seyahatte Kurulan Düşünce" başlı̆̆ı altında Tocqueville’in seyahatlerini ve bunların onun düşüncesini nasıl etkilediğini işler. Zira Tocqueville'i anlamak, onun gezilerini anlama zorunluluğundan geçer. Onun yaşamı durağan olmadığı gibi düşünceleri de masa başında inşa edilmiş değildir. Bu bağlamda Sunar'ın kronoloji kısmında Tocqueville’in ölümünü “son seyahatine çıkış” olarak ele alması oldukça manidardır. Sunar, onun yaptığı gezileri ele alırken Almanya ve Fransa içinde yaptığı gezilere değinmez. Bölümler içerisinde kendine yer bulamayan bu gezilere, kronoloji bölümü altında kısaca değinilmiştir. Kitap, genel hatları ile Tocqueville'in sosyal teorisi bağlamında ilerlediği için bu konulara değinmemesi bir zaaf olarak karşımıza çıkar. Ancak bu durum çalışmanın etkisini azaltmamaktadır. Bu konular başka bir çalışmanın konusu olmak üzere ilgilenenlerini beklemektedi r. Sunar'ın hassasiyetle üzerinde durduğu seyahatler ise Tocqueville'in Amerika, İngiltere ve Cezayir'e yaptı̆̆ı gezilerdir. Özellikle Amerika'da Demokrasi ile tanınan düşünürün Amerika seyahati detaylı bir şekilde incelenmiştir. Tocqueville bu seyahati, tanıştığı günden hayatının sonuna dek birlikteliğini sürdürdüğü en yakın arkadaşı Beaumont ile yapar. Gezinin görünen sebebi, ABD cezaevi sistemini 
inceleyerek Fransa ile bir karşılaştırmasını sunmaktı (s. 26). Ancak onun için bu sebep, Amerika yolculuğunun yalnızca garantisi mahiyetindeydi. Zira onun asıl sebebi, Amerika'ya karşı olan merakıydı (s. 25). Seyahatin sonucu olarak Amerika'da Demokra si'yi kaleme almıştı. Bu eser, Amerika'nın sosyal ve siyasi yaşamına tanıklık etmek isteyenler için oldukça önemli hususları içerir. Kitabın Amerika'da Demokrasi: Yükselen Bir Ülkenin Anatomisi başlıklı bölümünde Sunar, okuyucuya eserin oluşumunu, amacını ve konusunu, eserin üslubunu, Tocqueville'in olayları nasıl ele aldığını ve Amerika-Fransa farkını ortaya koymaktadır. O, bir milliyetçi olarak dönemin buhranından çıkış yolu aramıştır. Bu bağlam onu Amerika'ya yöneltmiştir.

Tocqueville, kitabın isminde belirtildiği gibi “modern dönemin çelişkileri karşısında bir düşünür" olarak anılabilir. Zira o, yeni sistemin yol açacağı sorunları ve doğurduğu çelişkileri kendi döneminden sezmiştir. Bu bağlamda o, Amerika'yı bu sistemin bir örneği, betimleyicisi olarak gören ilk düşünürdür (s. 93). Bu ülke geleceğin bir temsilcisi (s. 93) ve eğer durdurulamazsa modern dönemin yol açacağ1 aşırılıkların bir göstergesi (s. 82) olarak tüm gerçekliği ile karşımızda durmaktadır. Sunar, bu ülkenin eşitlik, demokrasi ve özgürlük altında eşitsizliği, despotizmi ve köleliği doğurduğunu söyler (s. 81-82).

Sunar'ın üstünde önemle durduğu seyahatlerden bir diğeri de Tocqueville'in İngilte re ziyaretleridir. Tocqueville, İngiltere'ye olan ilgisini yine Fransiz vatanperverliğine borçludur. Zira o, İngiltere karşısında Fransa'nın çıkarlarını koruma amacı (s. 56) çerçevesinde bu ülkeye yoğun bir eğilim göstermiştir. Bu bağlamda İngiltere, sanayinin toplumda nasıl bir krize yol açacağını göstermesi bakımından (s. 53) ve Hindistan'da uyguladığı sömürgecilik yönetimi bakımından (s. 54) incelenmeye değer bir ülkedir. Çünkü Tocqueville'in temel sorunlarını, yeni düzen ve sömürgecilik-kölelik konuları oluşturur (s. 17-18). Onun Cezayir'e yaptığı gezilerde bu bağlamla ilişkili olarak gerçekleşme şansı bulmuştur. Cezayir'e iki gezi düzenlemiş ve bölgenin durumunu yakından görme firsatı bulmuştur. Yaptığı gezilerde Cezayir'in nasıl elde tutulacağı, onun için önemli bir araştırma konusudur. Zira büyük bir ulus olmak isteyenler için sömürgeciliğe başvurmak kaçınılmazdı (s. 123). Ana mesele ise "Peki bu sömürgeler nasıl yönetilebilir?” sorusuydu. Tocqueville için sömürge yönetiminde Fransa şiddete başvurmaktan kaçınamazdı. Uzun vadede sömürgeler, şiddet ile elde tutulamasa dahi bir kontrol sağlanana kadar şiddet gerekliydi (s. 58). Çünkü o, Fransa içindeki şiddeti ve despotizmi dağıtmanın yolunu, Cezayir'deki despotizm olarak görür (s. 159). Ancak askerî müdahalenin oldukça kanlı bir noktaya ulaşmasının ardından Tocqueville, artık Cezayir üzerinde askerin değil sivillerin söz sahibi olması gerektiğini düşünür (s. 124). Böylece yerleşimci sömürge modeli hakkında çalışmaya başlamıştır. Ancak bu modelin uygulanabilmesi için mülkiyet sorunun çözülmesi gerekiyordu. Topraklar, Cezayirlilerin elinden 
alınmalı (s. 128), yeni yerleşimcilerin eline verilmeliydi. Kısacası onun öngördüğü çözüm, "modern mülkiyet için mülksüzleştirme" idi (s. 129). Tocqueville için Osmanlı'nın Cezayir'de uyguladığı yönetim modeli de bir merak konusuydu (s. 117). Ancak Sunar, bu konuyu dipnotta vererek ayrıntıya girmemektedir. Cezayir'deki diğer bir sorun da köleliktir. Köleliğin kaldırılmasını genel çerçevede ahlaki bir sorun olmaktan ziyade özelde Fransa'nın menfaatlerini korumak amacı ile istemiştir. Zira o dönemde İngiltere, kendi sömürgelerinde köleliği ilga etmişti (s. 151). Bu durum Cezayir halkı nezdine öğrenilip ayaklanmalara neden olursa Fransa'nın menfaati zedelenebilirdi. Tocqueville'in köleliğin kalkmasını istemesinin bir diğer nedeni de kölelerin sanayi işçileri ile beraber yaşayamayıp bir çatışmaya sebebiyet verebilir olma durumuydu (s. 157). Bu gibi durumlardan ötürü Tocqueville, köleliğin kalkması gerektiğini savunuyordu.

Modernitenin doğurduğu kavramlar ve yol açtığ sorunlar, Tocqueville'in ekseriyetle üzerinde durduğu ana konulardandır. Buna bağlı olarak eşitlik, zaman içinde ortaya çıkmış bir olgudur. Eşitlik ona göre kaçınılmaz bir oluşumdur (s. 72). Sunar, onun iki şekilde eşitlik fikrinden endişe duyduğunu dile getirir. İlk olarak eşit oy hakkı sonucu çoğunluğun yol açacağını düşündüğü zorbalık, ikinci olarak ise burjuvanın yol açacağı merkezîleşme ve despotizm (s. 72). O hâlde çalışmada önemli bir yeri işgal eden despotizmin eşitlik bağlamında kullanıldığını söyleyebiliriz. Zira Tocqueville, burjuvanın sürdüğü egemenliğin yumuşak despotizme yol açtığ1 kanaatindedir (s. 102). Sunar, Tocqueville'in burjuvaziye olan bakış açısının dönemin diğer düşünürlerinden ayrıldığını ve kendinden sonra gelecek olan modernite eleştirmenleri ile benzer bir noktada buluştuğunu dile getirir (s. 108). Kısaca özetlemek gerekirse diyebiliriz ki "herkes eşittir ama bazıları daha eşittir" fikri, kendini Tocqueville düşüncesinde hissettirmiştir. Baskıcı güçlerden kurtulmak isteyen toplum, eşitlik fikrine dayalı yeni bir düzen kurmuştur. Ancak belli bir süre sonra eşitlik fikri, yeni yönetici sınıfın lehinde işleme konulur. Yani eşitlik naraları atanlar artık daha eşit bir hâle gelerek despotizme yol açmaktadır. Bu bağlamda Tocqueville'in 'burjuvaziyi yeni aristokrasi' (s. 108) olarak nitelemesi oldukça manidardır.

Tocqueville'i dönemin diğer düşünürlerinden farklı kılan yönü, onu bir kategori altında ele almanın zorluğundan kaynaklanır. Bu bağlamda Sunar, Tocqueville'i üç görüşün sentezi olarak ortaya koyar; liberal, muhafazakâr ve radikal. Çünkü o, bu üç gruba dâhil düşünürlerin görüşlerinin bir karışımını sergilemektedir. Genel olarak o, mecliste liberallerle birlikte hareket etmiştir (s. 66). Ancak onun liberallere yakın olması, onlarla yeri geldiğinde zıt düşmesini engellememiştir. Zira sömürgelerde şiddet konusunda o, liberallerle zit düşmektedir. 
Sunar, eserde yeri geldikçe Tocqueville'in düşüncesini eleştirerek onun bütün hususla rı göremediğini ifade etmektedir. Örneğin o, dışarıya yöneltilen şiddetin zamanı gelince Fransa'yı saracağını öngörememiştir (s. 138). Benzer şekilde onun gözlem yanlışları ve bazı ihmallerinin oluşu birçok kişi tarafından dile getirilmiştir (s. 89). Fakat Sunar her ne kadar yeri geldiğinde onu eleştirip çelişkilerini ortaya koysa da onun gerçekten iyi bir gözlemci olduğunu sıklıkla dile getirir. Tocqueville'in dönemin diğer düşünlerinden farklılaşan fikirleri, öngörülerinin ilerleyen zamanlarda gerçekleşmesi, birçok kişinin göremediklerini ortaya koymaya çalışması onu önemli bir yere koymamamızı gerektirir. Bu bağlamda Tocqueville'i Türkiye'ye tanıtacak farklı alanlardaki çalışmalara ihtiyaç duymaktayız. Tocqueville en başta tarih, siyaset ve sosyoloji gibi alanlarda çalışmak isteyen araştırmacılar için ilgilenilmesi gereken bir düşünür olarak karşımızda durmaktadır.

Kitabın geneline bakacak olursak yazar, çalışma boyunca oldukça anlaşılır ve akıcı bir üslup kullanır. Bu da okuyucular için çalışmayı zevkli hâle getirmektedir. Sunar, görüşlerini tutarlı ve mantıklı bir şekilde ortaya koymaktadır. Okuyucunun zihninde anlatılmak ve vurgulanmak istenen konuyu canlandırmaktadır. Bu da kitabın okunmasını ve anlaşılmasını kolaylaştıran önemli bir etmendir. Öyle ki Tocqueville'in gelgitli düşünce tarzı, çalışmada oldukça berraklaştırılarak sunulmaktadır. Kitabın sistemli bir şekilde ele alınması bu durum üzerinde oldukça etkilidir. Bu bağlamda konular birbirleri ile irtibatlı bir şekilde verilmektedir. Çalışma kısa olmakla beraber Tocqueville hakkında bütünlüklü bir fikir sunar. Sunar bunu yaparken de ortaya koyduğu düşünceleri Tocqueville'den atıfla yahut alıntı ile güçlendirir. Ancak çalışmanın hacminin darlığı sebebi ile bazı konulara değinilmemiş bazı konular ise daha dar kapsamda ele alınmaktadır. Yazar, hakkında detaya girmediği konuların bir kısmı için okuyucuya bir yönlendirme yapar. Sunar, bir araştırmacı olarak Tocqueville'i kapsamlı bir şekilde araştırmaktadır. Onun Tocqueville araştırmalarının kapsamı, çalışmayı daha güvenilir yapmaktadır. Böylece eleştirel, özlü ve sistematik bir şekilde Tocqueville’i tanımak isteyenler için kitap oldukça önemli bir çalışma olarak ilgilenenlerini beklemektedir.

\section{Kaynakça | References}

Çağla, C. (2007). Tocqueville ve özgürlük (1. Baskı). İstanbul: Belge Yayınları.

Gürbüz, B. (2012). Tocqueville'in Cezayir raporlarında doğa yasaları ve güvenlik. Güvenlik Stratejileri Dergisi, 16, 21-46.

Özyurt, C. (2007). Tocqueville'de demokratik toplumun doğası. Muhafazakâr Düşünce Dergisi, 12, 23-43. 